there is any change, all changes must be most carefully shown in any manner the artist may prefer. 3. Especially note all long streamers. 4. All tints and change of tint, and whether the colour is distributed in patches or in layers concentric with the moon, or in connection with the prominences. 5. Whether it consists of a level patch of luminous haze or radiating beams of light, or of bundles of hyperbolic rays. 6. If of radiating or hyperbolic beams, whether they are evenly distributed all round, or in groups only. 7. Whether the dark intervals between such radiating beams are constant or fluctuating. 8. Whether it is concentric with the moon. 9. Whether it is equally intense all round the moon. Io. Whether the outer border exhibits any coruscations, or whether its definition is permanent and equally pronounced all round. II. Whether the light of the Corona is more intense or less so in the immediate neighbourhood of the prominences. 12. How much darker the moon's disc is than the sky.

\section{ENERGY, AND PROF. BAIN'S LOGIC}

[EXTRACT FROM PROF. TAIT'S OPENING ADDRESS to THE UNIVERSITY OF EDINBURGH, Nov. 2, 187o]

THE so-called Laws of Motion first explicitly stated, as we now employ them, by Newton in the Principia, are partly due to Galileo, partly to his immediate successors. Like all great physical discoveries, they were more or less clearly seen by many philosophers about the time in which Newton threw them into the simple, and yet comprehensive, form in which we now use them. As ordinarily understood, they embrace the results of observation and experiment as to the action of force on matter. The first tells us how matter behaves when not acted on by force, and therefore shows us how to detect the action of a force. The second tells us how to measure the force by its effects, and how to calculate the action of a force or forces acting on a mere particle of matter. The third, as directly interpreted, shows how to apply the other two to the motion of masses or of groups of particles. With these alone we have the foundation of an enormous portion of the science of Dynamics, and we require merely a sufficiently powerful mathematical process to enable us to develop to their utmost the calculations necessary for the determination of equilibrium or motion of any set of masses whatever, so long as the motion is visible, or capable of being rendered visible by a microscope,

But we require something more before we can extend mathematical calculations-which, be it ever remembered, are necessary in physics solely on account of the imperfections of our intellect; merely saving us an intolerable amount of thought which would otherwise be wasted on petty details-something more, I say, is required before we can apply our mathematics to Heat, Electricity, Chemical Action, \&c., \&c.

Curiously enough, that something was foreseen and provided for by the keen intellect of Newton. He gave it in the form of a second mode of interpreting his third law, quite distinct from the ordinary one, which is the wellknown assertion that "Action and Reaction are equal and opposite." Instead of using the terms Action and Reaction in the sense of mere pressures or tensions, he shows that the law will equally hold if they stand for what are now called rates of spendino or of receiving energy ; or, in more familiar language, rates of doing work. So that whenever there is transference of energy from one body to another, the one gains exactly as much as the other loses. This is at present the grandest physical law known. That we may understand it better, let us take first a simple physical fact, but one of a somewhat analogous nature. It is a comparatively recent discovery that matter is indestructible, yet so important that without it we may be certain that chemistry could never have become a science. If a chemist were not assured by experiment that no quantity of matter, however small, is ever put out of existence, submit it to what ordeals he may, what confidence could he have in the results of an analysis? Or again, where would his science be if new matter could suddenly make its appearance? The balance is his most important instrument, but without the confidence (derived from experiment) that matter cannot change in quantity, its indications would be of no value to him.

So it is, but in a more extended sphere, with the Natural Philosopher, and it is a source of legitimate pride to us, that as Newton first hinted at this grand modern generalisation, and first gave the mathematical method naturally fitted for its development, so it is to this country again, and mainly to Dr. Joule of Manchester, that we owe the proof (which must, of course, be experimental to be valid) that energy is, like matter, indestructible. It is, therefore, in the usual sense of the word, as REAL as matter. In fact, ithe physical phenomena of the Universe (excluding in the meantime; on account of our utter ignorance, some of those connected with life) depend upon matter and energy alone. Different combinations of matter constitute the subject of our chemistry; different groupings of molecules as well as of masses, and different distribution of Energy, form the rest of our Natural Philosophy. Hence the overwhelming importance of this real something, Energy, in the whole of Physical Science.

I shall devote the rest of my time this morning to very elementary notions connected with energy and this grand law of Nature. But before I do so I have a few words to say about another work in which the principles of Natural Philosophy are discussed; a book infinitely more likely than that of Hegel (whose absurdities I have already pointed out to you) to fall into your hands. It is now not a dreamy and dogmatic German, evolving everything from himself, and railing at physical facts as well as at exquisite methods in mathematics, with whom we have to do-it is on the contrary, a hard-headed Scotsman, and a Professor in one of our Universities. We have here no evolution from consciousness to laugh at, no sneering at experimental science ; we have to guard against dangerous misconceptions of the truths discovered by physicists ; mistakes all the more dangerous that they are honestly held, and that they have been assigned a prominent place in a textbook which many of you may have at some time to read; and especially because, as students, you are peculiarly liable to be led away by $e x$ cathedrâ statements. For obvious reasons I cannot take many examples now; in the more abstruse, the statement itself, and the exposition of its error, would be alike unintelligible to you; in the simpler ones you may be trusted to see the error for yourselves.

The first I quote is from what is called the Logic of Physics, and is, to a certain extent, personal. "Volume and mass rightly precede density in order of definition. Messrs. Thomson and Tait make density precede mass." And we do so, we think, very logically, because density is a specific property of matter, unalterable in general, except to a very small extent, by physical processes, while volume and mass are absolutely indefinite, depending as they do upon the quantity of matter spoken of.

Again, "In the transfer of force, nothing is lost. The mechanical momentum transmuted into heat is fully accounted for in the heat produced: by proper arrangements it could all be gained back." The last nine words, however they may be interpreted, are essentially false : in fact they contain an explicit denial of the second law of thermodynamics upon which Sir W. Thomson based his grand law of Dissipation of Energy, one of the most im. 
portant of his many splendid contributions to physics, and one having the most direct bearing upon the future of the physical universe. The rest of the statement, as it stands, is also false. It may be made correct by writing one of the words, work, power, potency, or preferably energy, in place of force, and also in place of momentum. What would be thought of a man who should say-" I paid six weeks for it," meaning "pounds" by "weeks." For "momentum" cannot be transformed or "transmuted" at all, it remains for ever unchanged.

Again, when bodies impinge on one another, "the rise of temperature is exactly proportioned to the visible momentum destroyed." Let us put the correct word "energy" in the place of momentum, and we find that this asserts the startling physical fact that the specific heat of every body is the same at all temperatures. If we take the statement as it stands without correction, it is simply nonsense.

Again, "the foot pound, meaning the force expended in raising one pound weight one foot, which is the same as a (sic) momentum of one pound moving at eight feet per second."

Raising one pound weight one foot is a feat which, by proper combinations of machinery, may be effected by any given force whatever, be it the weight of a grain or of a million tons. But a "foot pound," and the "momentum of one pound moving at eight feet per second" cannot possibly be compared with each other, any more than a cubic yard can be expressed as a number of square yards, or the height of a mountain in acres, roods, and poles.

You will see that the error in the examples I have just chosen (excepting of course the fatal one about restoration of energy) is in great part due to the misuse of words. Yet it is from a treatise on Logic that I have quoted !

The essence of the lesson taught by all this is simply the conviction that scientific knowledge has reached such an immense development that no one man can now possibly master thoroughly more than one or two of its many branches. There can be no "Admirable Crichtons" in our days. The greatest logician the world has produced, or is likely to produce, for many a long day, the lamented George Boole, more than once expressed his regret that a systematic logical treatment of human knowledge, even in moderate compass, and going little farther than the elements in each branch, had become absolutely impossible as the work of one man-impossible, that is, for a man who revolted at the idea of publishing anything he knew to be defective.

\section{MOUNTAIN CLIMBING}

I $N$ the number of NATURE for June 23, I870, I described an ascent of Mount Etna which $I$ made on March 4 of this year, with an excellent guide, Pietro Cravagna,

I now propose to make some remarks on a few points of interest with regard to mountain climbing. One of the most important of these is the alleged lowering of the internal temperature of the body under such conditions.

During two ascents of Mont Blanc made on the 7 th and 26th of August, 1868, by Dr. Lortet, of Lyons, and Dr. Marcet, of London, and described by Dr. Lortet in the Lyon Médical of September 26, I869, experiments made apparently with great precaution on Dr, Lortet himself with a registering maximum thermometer (of Walferdin), by which (between $+30^{\circ} \mathrm{C}$. and $+40^{\circ} \mathrm{C}$.) hundredths of a degree could be appreciated, showed that the internal temperature of the body under such conditions is lowered to a very remarkable extent.

I will quote Dr, Lortet's own words : "A jeun et exactement dans les mêmes conditions, pendant la marche, la décroissance de la température intérieure du corps est très-remarquable, elle est à peu près proportionelle à l'altitude a laquelle on se trouve."

In effect, from the table given in the paper referred to, I find that during the first ascents the internal temperature descended gradually from $36.3^{\circ} \mathrm{C}$. (that during exercise at Chamounix, $\mathrm{I}, 050$ metres above the sea) to $32^{\circ} \mathrm{C}$. at the summit of Mont Blanc (4,810 metres above the sea); while during the second ascent the difference was from $353^{\circ} \mathrm{C}$. to $31.8^{\circ} \mathrm{C}$.

Dr. Lortet found that as soon as he stopped for a few minutes, the temperature of his body rose briskly to the normal standard, except on the summit itself, where "il a fallu près d'une demi-heure pour que le thermomètre atteignit sa hauteur habituelle."

During digestion, in spite of the exercise being taken, the temperature remains normal, or even rises; but this does not last long: "Une heure à peine après avoir mangé, le corps se refroidit de nouveau par les efforts." The descent of the temperature of the body under such conditions, then, amounts sometimes to more than $4^{\circ} \mathrm{C}$. ; and if we take the difference between the normal temperature of the body at rest, and that observed by these experimenters on the top of Mont Blanc, the difference amounts in one case to $5^{\circ} \mathrm{C}$., "abaîssement énorme pour les mammifères dont la température était reputé constante!" as Dr. Lortet justly exclaims.

Now Mount Etna is particularly suitable for such experiments; one begins to walk either at Nicolosi, or preferably at the Casa del Bosco, and one has nothing to do but to go straight up ; there is nothing in the way, it is simply a long "grind" of some five or six hours or more, according to the state of the snow. A series of misfortunes with my maximum thermometers prevented my repeating the above-described observations, and I have referred to them at such length in the hope that some one may be induced to take the excellent opportunity afforded by the expedition to Sicily of deciding so important a point.

The state of the circulation is hardly less important than that of the internal temperature.

Dr. Lortet found that the pulse increased in frequency from 64 per minute at Chamounix to 172 on the summit of Mont Blanc, and he was further enabled, by means of the sphygmograph, to make some observations as to the state of the pulse at various altitudes. In ascending Etna I made some comparative observations on the frequency of my guide's pulse as compared with my own, which show some points of interest.

At the Casa del Bosco my pulse was 68, my guide's 74 ; we had both ridden to that point, and the difference is probably an illustration of the established fact that the circulation of persons living in mountainous districts is quicker than that of those living in plains. On arriving at the summit of Etna after a ride of an hour and a quarter (from the Casa del Bosco), a rest of fifteen minutes, and a stiff walk of three and a quarter hours over dry, hard, snow (an exceptionally easy ascent), ${ }^{*}$ my pulse was very irregular, and about I I 4 or II 5 to the minute, while the guide's was only 89 - that is to say, that mine had increased 46 beats in frequency, his only 15 ; or mine was about $\frac{2}{3}$ rds, his only about $\frac{1}{5}$ th, as fast again; showing the slight effect of such ascents on those who are used to them, and who live habitually in mountainous countries.

But this was still more forcibly illustrated by the state of our pulses after a very quick descent, a regular trot all the way (we had stayed two hours at the summit, and eaten a hearty breakfast); at the place where we left the mules, I found that while my pulse, after a minute or two's rest, was at 106 or 107, the guide's was at 99 or 100 ; mine being 8 beats less than it was on arriving at the top, his Io beats more; his circulation was less disturbed by * Later on in the month of March, when much snow had recently fallen
the Rev. A. G. Girdlestone and I, with two other friends, made an ascent: it took us nearly eight hours to walk from the Casa del Bosco to the Casa degli
Inglesi, and we saw nothing but a very heavy snow-storm. 